\title{
New Zealanders' attitudes to milk: implications for public health
}

\author{
Carol A Wham ${ }^{1, *}$ and Anthony Worsley ${ }^{2}$ \\ 'Institute of Food, Nutrition and Human Health, Massey University, Albany Campus, Private Bag 102 904, North \\ Shore Mail Centre, Auckland, New Zealand: ${ }^{2}$ School of Health Sciences, Deakin University, 221 Burwood Highway, \\ Burwood, Victoria 3125, Australia
}

Submitted 13 December 2001: Accepted 3 May 2002

\begin{abstract}
Objective: To identify consumer attitudes and beliefs about (liquid) milk that may be barriers to consumption.

Design: Two random-quota telephone surveys conducted in Auckland one year apart. Respondents were questioned about their usual milk intake and their attitudes to milk. The questionnaire included attitude items that reflected the main themes of consumer interest in milk.

Setting: New Zealand.

Subjects: Seven hundred and thirteen respondents in the baseline survey and a separate sample of 719 respondents in the follow-up survey.

Results: At least one-third of the respondents consumed less than a glass $(250 \mathrm{ml})$ of milk a day. Non-consumption was highest in young women (15\%). People's concerns about milk related to what was important in their lives; what threatens them physically and emotionally. Women held more positive attitudes but they were concerned about the fat content of milk. Men were less aware of milk's nutritional benefits and as a result were less appreciative of its value.

Conclusions: There is an opportunity to develop public health initiatives to address the barriers to drinking milk. Industry-health alliances may be an effective means to provide positive nutrition messages about milk and to engage the support of health professionals.
\end{abstract}

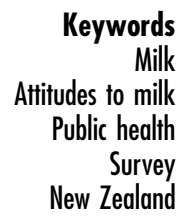

In New Zealand the annual per capita consumption of milk has declined by $30 \%$ in the last 20 years, to 94 litres in $1997^{1,2}$. A similar trend is present in other Western countries $^{3}$. The decline in New Zealand is partly due to environmental influences that have affected the availability, purchase and consumption of milk. These influences include the discontinuation of the subsidised school milk scheme in 1967, removal in 1985 of the government subsidy placed on milk, and the impact of dairy export returns on milk pricing. Milk as a drink, both in and out of the home, has endured ruthless competition from soft drinks. Their range of products, packaging and availability has increased and their low material costs enable them to be extensively promoted. In addition, lifestyle factors have influenced the habitual food choices of the consumer, such as decreased breakfast consumption and greater use of convenience foods. As a result, less milk is used as a beverage, on cereals and in cooking.

The decline in milk consumption has important consequences for the nutritional health of the population, especially its bone health. The 1997 National Nutrition Survey showed that New Zealanders over the age of 15 years obtain $37 \%$ of their calcium intake from milk ${ }^{4}$. Other sources of calcium were cheese (11\%), bread (6\%), vegetables, non-alcoholic beverages and dairy products (all 5\%). The survey identified that $20 \%$ of the New Zealand population had an inadequate intake of calcium. Inadequate intakes were higher among women (25\%) than men (14\%), especially in those aged 15 to 18 years (37\% of women and $33 \%$ of men $)^{4}$.

Milk is a complex food and contains many nutrients that provide benefits as well as threats to its consumption. Consumers' perceptions of these aspects of milk have not previously been examined in an integrated study.

The Cognitive Structure Model for Food Related Lifestyle $^{5}$ serves as a useful theoretical framework to examine the extent to which usage situations, attitudes and beliefs influence milk consumption. The model proposes that seven key sets of variables make up consumers' lifestyles. It illustrates how food consumption depends on a number of lifestyle factors such as shopping knowledge and skills ('scripts'), packaging, cost, habitual use, and attitudes and beliefs. Several studies have demonstrated that attitudes and beliefs about particular foods predict their consumption, and these appear to overrule other lifestyle factors. Examples include milks of varying fat content ${ }^{6}$, consumption of high-fat foods ${ }^{7-9}$, consumption of low-fat milk $^{10}$, and beef ${ }^{11}$, fruit and 
vegetable $^{12}$ and hamburger consumption ${ }^{13}$. Therefore it is likely that attitudinal factors may underlie declining levels of milk consumption. For example, beliefs about milk's nutrient content (e.g. calcium, protein, calories) and functionality (e.g. 'goes well with other items', 'quenches thirst') have been found to affect milk consumption positively, and beliefs about gaining weight and cost affect it negatively ${ }^{14}$. Amongst participants who completed a mail survey of nutrition knowledge, attitudes and behaviour, it was found that the nutrition knowledge score was significantly correlated with the frequency of milk intake and attempts to increase dietary calcium intake ${ }^{15}$.

Other researchers have illustrated that some women's consumption of low-fat milk is influenced by cognitive factors in addition to sensory and organoleptic factors ${ }^{16}$. Respondents completed food frequency and milk attitude questionnaires and performed sensory evaluations of different milk samples. Sensory evaluation indicated that subjects liked whole milk more than low-fat milk and as the percentage of fat increased, so did the sensory score for liking. Nevertheless, more subjects believed lower-fat milks to be 'good for me'. Again this suggests that positive attitudes are important predictors of greater milk consumption.

However, food choice is not just about attitudes and beliefs. Several studies have shown that membership of social categories such as gender, age, education, occupational status and ethnicity may influence food selection behaviours and the attitudes and beliefs on which they depend ${ }^{17-20}$. There may be attitudinal factors underlying declining milk consumption that require changing, and this may lead to the development of interventions to promote more healthful behaviours.

In this study the aim was to identify demographic characteristics and cognitive factors that may influence milk consumption. Therefore, usual milk intake and consumer attitudes and beliefs to milk were investigated one year apart. This provided a means to assess the stability of attitudes over the study period.

\section{Methods}

\section{Procedure}

Two telephone surveys were conducted over a twelvemonth period in the Auckland region. Respondents were questioned about their usual milk intake and their beliefs about milk. The objective was to contact 720 residential households to complete the questionnaire. Proportions in the New Zealand population (Table 1) determined the sample size with quotas for age and gender. There were no other inclusion or exclusion criteria. A central telephone interviewing facility was used to conduct the telephone interviews, which were conducted on weekdays both during the day and in the evening. To overcome any bias created by women answering the phone, each
Table 1 Proposed age and gender quota for the baseline survey sample

\begin{tabular}{lrcr}
\hline & Men & Women & Total \\
\hline $16-20$ years & 34 & 40 & 74 \\
$21-35$ years & 102 & 110 & 212 \\
$35-50$ years & 84 & 82 & 166 \\
$51-65$ years & 87 & 86 & 173 \\
65+ years & 48 & 47 & 95 \\
Total & 355 & 365 & 720 \\
\hline
\end{tabular}

interviewer asked to speak to the adult in the household who last had a birthday. One of the limitations was that the protocol did not allow for re-tries for a number that did not respond. This was in accordance with the Direct Marketing Association's Code of Ethics. Another random number replaced the call. Although this resulted in a low response rate $(<20 \%)$, in demographic terms the samples were similar to the national population census and only slightly overestimated people who were not in the paid workforce.

\section{Questionnaire}

From a literature review of consumer attitudes to milk consumption, 27 attitude items were selected for inclusion in a survey questionnaire to reflect the four main themes of consumers' interest in milk:

- sensory factors;

- cost and usage;

- health and nutrition; and

- age and gender requirements.

The respondents were asked to give one of five responses depending on their degree of agreement with each attitude statement. They were also asked about their daily milk consumption, either as a drink or added to cereals, tea and coffee. Responses were recorded as: less than $1 / 4$ litre per day, between $1 / 4$ and $1 / 2$ litre per day, more than $1 / 2$ litre per day, or none at all.

\section{Data analysis}

Both waves of the survey were analysed separately using the SPSS package (version 7.5). Cross-tabulations of the data from each wave were undertaken to compare the percentage agreement with the attitude statements across sex, age, education, occupation, ethnic and milk consumption groups. To avoid over dependence on spurious or chance differences in the observed results, a conservative alpha level of 0.01 was used. Comparisons of the mean scores for the attitude items in the baseline and follow-up surveys showed that they were very stable $(r=$ $0.937, P=0.0001)$.

Milk consumption by demographic characteristics and attitudes was predicted using CHAID, a program included in SPSS. CHAID (Chi-squared Automatic Interaction Detector) performs segmentation modelling in which a sample is divided into two or more distinct groups based 
on combinations of categories of the 'best' predictor(s) of a dependent variable ${ }^{21}$.

\section{Respondent characteristics}

There were 713 respondents in the baseline survey and 719 respondents in the follow-up survey, similar to their proportions in the New Zealand population (Table 2). Their ages ranged between 16 and 94 years. Nearly twothirds $(63 \%)$ of the sample in the baseline survey were European New Zealanders. There were slightly more European women (66\%) than men (60\%). Thirteen per cent of the sample was Maori, 14\% Pacific Islands people and 10\% Asian respondents. The percentages of Pacific Islands and Asian men were slightly higher than for women. Compared with the national sample, European and Maori New Zealanders were under-represented and Pacific Islands and Asian people were over-represented. Similar trends were observed in the follow-up survey. The over-representation of Pacific Islands and Asian people reflects their greater numbers in the Auckland region.

\section{Results}

In both surveys, over one-third of the respondents consumed less than a glass $(250 \mathrm{ml})$ of milk a day. Although it is likely that additional milk was consumed from other dairy sources, it is clear that the consumption of milk as a beverage was minimal. In general, men drank more milk and a higher percentage of women were nonconsumers. Overall, $9.4 \%$ of young people (16 to 30 years) consumed no milk at all. Non-consumption was higher among young women (15\%) whilst heavy consumption (more than two glasses a day) was higher among young men (>40\%). Amongst men, consumption declined with age.

In both surveys the strongest attitudinal predictor of low milk consumption was 'milk is expensive compared to fizzy drinks' (Fig. 1). In the baseline survey those who agreed (or were unsure) consumed smaller amounts of milk (less than $250 \mathrm{ml}$ ) than those who disagreed ( $45 \%$ and 29\%, respectively). The attitude 'adults over 65 need more milk than younger adults' was the best predictor of consumption among those who disagreed that 'milk is expensive compared to fizzy drinks'. Those who agreed or

Table 2 Age and sex of survey respondents

\begin{tabular}{|c|c|c|c|c|c|c|c|c|}
\hline \multirow[b]{2}{*}{ Age group (years) } & \multicolumn{4}{|c|}{$\begin{array}{c}\text { Baseline } \\
\text { survey, } 1997\end{array}$} & \multicolumn{4}{|c|}{$\begin{array}{c}\text { Follow-up survey, } \\
1998\end{array}$} \\
\hline & Men & $\%$ & Women & $\%$ & Men & $\%$ & Women & $\%$ \\
\hline $16-$ & 40 & 12 & 47 & 13 & 41 & 12 & 48 & 13 \\
\hline $21-35$ & 96 & 27 & 104 & 29 & 96 & 27 & 104 & 29 \\
\hline $36-50$ & 84 & 24 & 82 & 23 & 85 & 24 & 82 & 23 \\
\hline $51-64$ & 85 & 24 & 84 & 23 & 81 & 23 & 78 & 22 \\
\hline $65+$ & 44 & 13 & 47 & 13 & 51 & 14 & 53 & 15 \\
\hline Total & 349 & 100 & 364 & 100 & 354 & 100 & 365 & 100 \\
\hline
\end{tabular}

were unsure that adults over 65 need more milk consumed significantly lower amounts of milk than those who disagreed (32\% and 15\%, respectively). 'Milk is good value for money' was the best predictor of consumption among those who agreed or were unsure that adults over 65 need more milk. Those who disagreed that 'milk is good value for money' consumed significantly less milk than those who agreed or were unsure (48\% and 29\%, respectively).

Most (90\%) of the respondents understood that milk is a good source of calcium and is important for bone growth. Awareness about calcium and bone growth was lowest amongst Pacific Islands and Asian people, reflecting a difference in perceptions amongst New Zealand

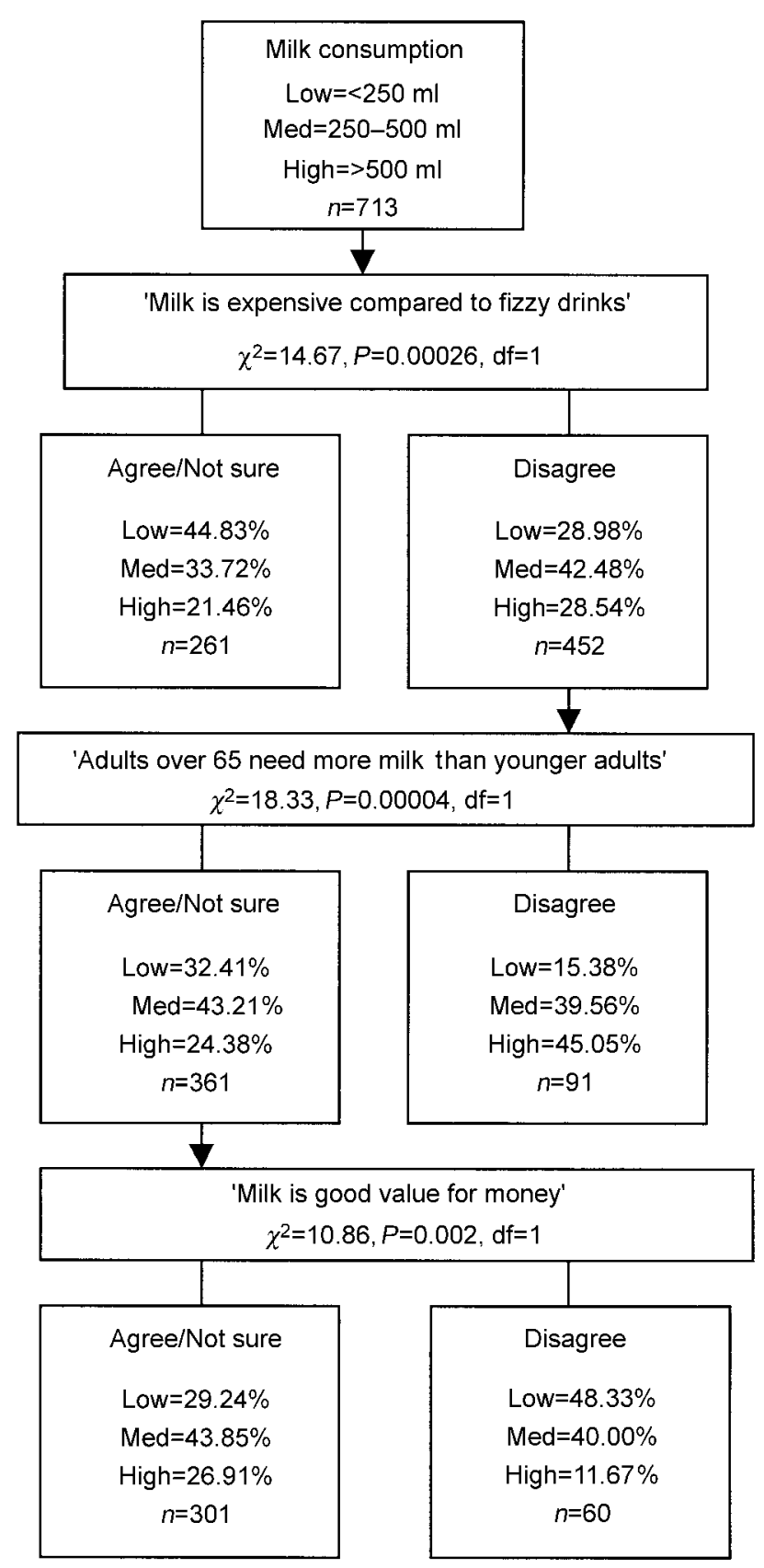

Fig. 1 Attitude predictors of milk consumption in baseline survey 
immigrants. Women were more aware than were men that milk is rich in calcium. Respondents over the age of 53 years tended to support the use of calcium supplements.

The majority of consumers agreed that 'milk is better for you than soft drinks', although about a quarter of younger people (aged 16 to 30 years), men and Pacific Islands and Asian people did not share this view. Indeed, a substantial proportion of respondents (one-third) thought that fruit juice was 'better for you than milk'.

About a third of the women and a quarter of the men believed that 'all milk is high in fat'. Indeed, the strongest attitudinal predictor of 'all milk is high in fat' in both surveys was agreement with 'fruit juice is better for you than milk'. This suggests that milk is not considered to be as healthy as fruit juice because of its high fat content.

In both surveys more than $27 \%$ of respondents agreed that 'milk can cause bigh blood cholesterol' and men agreed more than women. This finding supports the expectation that cholesterol would be perceived as a dominant negative nutrient linked to saturated fat intake. The perception that milk is high in cholesterol was related to increasing age and high occupational status.

Beliefs that 'milk causes allergies in a lot of children' were strongest amongst people over the age of 53 years. There was a higher agreement amongst NZ Maori, which may be related to the higher incidence of respiratory infections $^{22}$ and glue ear amongst their children ${ }^{23}$.

In general, women had more positive beliefs about the price and health benefits of milk. Men were more of the view that milk is for older people. They also felt obliged to drink it although they believed it was expensive compared with soft drinks (Table 3). Young people had more positive attitudes to liking milk during childhood but were the least positive about its value for money. Older people seemed to have misgivings about the taste of milk and appeared uncertain about the benefits of milk compared with calcium supplements. With reference to varieties of whole, regular, reduced and non-fat milk, older people were of the view that too many types of milk are available (Table 4).

\section{Discussion}

\section{Milk consumption}

Milk is an unpopular beverage choice for about one-third of New Zealanders. Gender was the strongest demographic predictor of milk consumption. In general, men drank more milk and a high percentage of women were non-consumers. Non-consumption of milk is a potential problem among some young women. There is a significant positive association between milk consumption up to age 25 and higher bone mass, which may be protective against age-related osteoporosis ${ }^{24}$. To maintain bone health in young women, public health initiatives and specific strategies are needed by the milk industry to target this group.

The hypothesis that respondents' attitudes to milk predicted their consumption was upheld. The strongest attitude predictor in both surveys was the statement ' milk. is expensive compared to fizzy drinks'. Those who agreed (or were unsure) consumed significantly smaller volumes of milk than those who disagreed. This suggests that among low volume milk consumers, cost may be a barrier. They may prefer soft drinks, which are less expensive. Further evidence for the role of cost in milk avoidance is related to some of the attitudes of those respondents who disagreed that 'milk is expensive compared to fizzy drinks'. Among this group agreement with the statement that 'adults over 65 need more milk than younger adults' predicted low consumption. This suggests low volume consumers might believe that milk is more important for older people. Among those who agreed (or were unsure) with this statement, disagreement with the attitude ' $m$ ilk is good value for money' predicted low consumption. This again implies cost is a barrier. The cost of milk has been identified as a problem by other investigators ${ }^{15}$. It suggests that the health benefits of milk are not realised.

An important part of increasing milk consumption is to make it as easy to consume as other beverages. Milk or milk-based drinks need the same prominent exposure as soft drinks. Therefore milk needs to be available in

Table 3 Percentage agreement with attitude statements in the baseline survey, comparison by sex

\begin{tabular}{|c|c|c|c|c|}
\hline \multirow[b]{2}{*}{ Attitude/belief } & \multicolumn{2}{|c|}{$\begin{array}{l}\text { Percentage } \\
\text { agreement }\end{array}$} & \multirow[b]{2}{*}{$\begin{array}{c}\text { Pearson } \\
\text { Chi-square* }^{*}\end{array}$} & \multirow[b]{2}{*}{$P$-value } \\
\hline & $\begin{array}{c}\text { Men } \\
(n=349)\end{array}$ & $\begin{array}{l}\text { Women } \\
(n=364)\end{array}$ & & \\
\hline Milk is good value for money & $63.3(9.5)$ & $72.0(13.5)$ & 35.959 & 0.001 \\
\hline Milk is better for you than fizzy drinks & $73.1(19.5)$ & $91.2(4.9)$ & 42.474 & 0.001 \\
\hline Milk can cause high blood cholesterol & $31.5(53.3)$ & $28.8(45.1)$ & 13.108 & 0.001 \\
\hline It is important to drink milk when you're on a weight-reducing diet & $29.8(45.8)$ & $21.2(44.0)$ & 12.038 & 0.002 \\
\hline Adults over 65 need more milk than young adults & $44.7(38.4)$ & $36.8(35.2)$ & 12.981 & 0.002 \\
\hline I only drink milk because I feel I should & $30.4(11.5)$ & $18.1(11.3)$ & 15.345 & 0.001 \\
\hline Milk is refreshing & $58.5(5.4)$ & $46.2(16.5)$ & 24.839 & 0.001 \\
\hline Milk is expensive compared to fizzy drinks & $21.5(14.3)$ & $11.0(26.4)$ & 24.876 & 0.001 \\
\hline
\end{tabular}

Percentage of responses as 'don't know' is given in parentheses.

${ }^{*} \mathrm{df}=2$. 
Table 4 Percentage agreement with attitude statements in the baseline survey, comparison by age group

\begin{tabular}{|c|c|c|c|c|c|}
\hline \multirow[b]{2}{*}{ Attitude/belief } & \multicolumn{3}{|c|}{ Percentage agreement } & \multirow[b]{2}{*}{$\begin{array}{c}\text { Pearson } \\
\text { Chi-square* }^{*}\end{array}$} & \multirow[b]{2}{*}{$P$-value } \\
\hline & $\begin{array}{c}16-30 \text { years } \\
(n=234)\end{array}$ & $\begin{array}{l}31-52 \text { years } \\
\quad(n=239)\end{array}$ & $\begin{array}{l}\text { Over } 53 \text { years } \\
\quad(n=240)\end{array}$ & & \\
\hline I used to like milk as a child & $80.8(6.4)$ & $68.6(10.9)$ & $61.7(27.9)$ & 55.890 & 0.001 \\
\hline Milk is good value for money & $61.1(23.5)$ & $71.5(11.3)$ & $70.4(5.8)$ & 35.941 & 0.001 \\
\hline Milk tastes good & $77.4(6.0)$ & $76.2(7.5)$ & $65.8(18.3)$ & 22.923 & 0.001 \\
\hline Drinking milk is better than taking calcium supplements & $63.7(24.4)$ & $68.6(18.0)$ & $51.3(35.4)$ & 20.860 & 0.001 \\
\hline There are too many types of milk available & $23.9(24.4)$ & $17.6(26.4)$ & $29.6(34.6)$ & 23.557 & 0.001 \\
\hline
\end{tabular}

Percentage of responses as 'don't know' is given in parentheses.

${ }^{*} \mathrm{df}=4$.

vending machines and cafes. In order to compete in these areas milk also needs a longer shelf life. It is also important that the milk industry should develop communications about the health benefits of milk to justify its higher price.

\section{Attitudes to milk}

The attitude items chosen for investigation were quite distinct. This was to ensure a broad coverage of the attitude domains related to milk. In general, most people had positive views about milk but several of the demographic groups had polarised opinions. Women tended to have greater knowledge about the calcium benefits of milk and were more of the view that milk is better for you than fizzy drinks. Men, however, were less convinced about milk's nutritional benefits and were less inclined to agree that milk is good value for money.

Pacific Islands and Asian people were less aware about the role of milk in bone growth and a third did not hold the view that milk is better for you than soft drinks. On the other hand, Pacific Islands people as well as men in general held the positive view that milk is refreshing. These findings suggest that the milk industry needs to work with health agencies in New Zealand to ensure that the education and health sectors provide positive messages about milk.

Older people were the most pessimistic about milk. They were less likely to agree that milk provides nutritional goodness and a substantial proportion were not convinced that milk has a good taste. Alternative products such as milk and juice blends, flavoured milk and milks for specific usage occasions (e.g. breakfast or as a nightcap) may provide an opportunity to promote higher consumption. Nearly half of the older people appeared to favour taking calcium supplements instead of milk. Therefore the milk industry must develop appropriate communications to this age group. Promotion of milk consumption by public health authorities may also help to reassure older people that milk is a useful and accessible source of calcium

Younger people had more positive views about milk but nevertheless it was not a popular choice for them. They had liked milk during their childhood but seemed to lack knowledge of milk's inherent benefits. As a result, they were least likely to agree that milk is good value and had the most positive attitudes to soft drinks. The successful targeting of energy drinks amongst young consumers suggests that a similar positioning may work for milkbased drinks. Young people could be coerced into drinking more milk if they knew how good it was for their body.

Amongst adults there is an apparent barrier to drinking milk because of inaccurate perceptions about its cholesterol content. Low-fat milks were generally not well understood. Targeted messages, illustrating that lowfat milks have negligible cholesterol content but important nutritional benefits, especially in relation to maintenance of strong bones, may help to increase consumption. This provides an opportunity for the milk industry to collaborate with the weight loss industry and the National Heart Foundation to provide positive communications about the benefits of low-fat milk.

Concerns about perceived allergenic properties of milk among children were evident in over a third of the respondents. The unease was greatest amongst older people (over 53 years) and NZ Maori. It had previously been shown that 19\% of New Zealanders believe allergies are related to eating dairy products ${ }^{25}$, but until now milk has not been directly implicated in consumer studies. It would be beneficial to provide health professionals and older people with up-to-date information about milk allergies. In addition, it may be helpful to develop culturally appropriate education materials for Maori in conjunction with Maori health workers.

\section{Conclusion}

In summary, low milk consumption is a potential problem for the nutritional status of some segments of the population, particularly for young women. Inspection of the respondents' expressed attitudes suggests that milk has become less relevant to people's lifestyles and the nutritional benefits of milk are not widely understood. Whilst negative attitudes to milk were not widespread, they may limit the potential to make milk an everyday part of modern life. The narrow focus of the perceived nutritional benefits of milk appears to have inhibited 
milk's popular appeal. The findings suggest that there are opportunities to provide targeted communications about the health benefits of milk. The development of enticing milk-based drinks, which can compete with other beverages such as soft drinks, may help to increase consumption.

\section{Acknowledgements}

Financial assistance to undertake this study was provided by the New Zealand Dietetic Association, Neige Todhunter Award.

\section{References}

1 New Zealand Milk Board Reports, 1945-1981.

2 Milk consumption reports. Statistics New Zealand, 19821997.

3 The world dairy situation. Bulletin of the International Dairy Federation. No. 323, 1997.

4 Ministry of Health. New Zealand Food: New Zealand People. Key results of the 1997 National Nutrition Survey. Wellington: Ministry of Health, 1999

5 Grunert KG, Brunso K, Bisp S. Food Related Life-style: Development of a Cross-culturally Valid Instrument for Market Surveillance. MAPP Working Paper No. 12. Aarhus: The Aarhus School of Business, 1993.

6 Tuorila $H$. Selection of milks with varying fat contents and related overall liking, attitudes, norms and intentions. Appetite 1987; 8: 1-14.

7 Shepherd R, Stockley L. Fat consumption and attitudes towards food with a high fat content. Hum. Nutr. Appl. Nutr. 1985; 39A: $431-42$.

8 Shepherd R, Stockley L. Nutrition knowledge, attitudes and fat consumption. J. Am. Diet. Assoc. 1997; 87: 615-9.

9 Towler G, Shepherd R. Application of Fishbein and Ajzen's expectancy-value model to understanding fat intake. Appetite 1992; 18: 15-27.

10 Shepherd R. Belief structure in relation to low fat milk consumption. J. Hum. Nutr. Diet. 1998; 1: 421-8.

11 Saap SG. Impact of nutritional knowledge within an expanded rational expectations model of beef consumption. J. Nutr. Educ. 1991; 23: 214-22.

12 Brug J, Lechner L, De Vries H. Psychosocial determinants of fruit and vegetable consumption. Appetite 1995; 25(3): 285-96.

13 Axelson ML, Brinberg D, Durand JH. Eating at a fast-food restaurant. A social psychological analysis. J. Nutr. Educ. 1983; 15: 94-8.

14 Tuorila H, Pangborn RM. Prediction of reported consumption of selected fat containing foods. Appetite 1988; 11: $81-95$.

15 Elbon SM, Johnson MA, Fischer JG. Developing an instrument to measure the influence of knowledge, behaviours, and attitudes on milk consumption patterns in older participants of a community wellness group: a pilot study. J. Nutr. Elder. 1996; 15(4): 21-37.

16 Brewer JL, Blake AJ, Rankin SA. Theory of reasoned action predicts milk consumption in women. J. Am. Diet. Assoc. 1999; 99(1): 39-44.

17 Rappoport L, Peters GR, Downey R. Gender and age differences in food cognition. Appetite 1993; 20: 33-52.

18 McConaghy J. Adults beliefs about the determinants of successful dietary change. Community Health Studies 1989; 13(4): 492-502.

19 Steele P, Dobson A, Alexander H. Who eats what? A comparison of dietary patterns among men and women in different occupational groups. Aust. J. Public Health 1991; 15(4): 286-95.

20 Metcalfe PA, Scragg RK, Tukuitonga CF. Dietary intakes of middle-aged European, Maori and Pacific Islands people living in New Zealand. N.Z. Med. J. 1998; 111: 310-3.

21 Hill DA, Delaney LM, Roncal S. A chi-square automatic interaction detection (CHAID) analysis of factors determining trauma outcomes. J. Trauma 1997; 42(1): 62-6.

22 Pearce NE, Davis PB, Smith AH. Mortality and social class in New Zealand. III: Male mortality by ethnic group. N.Z. Med. J. 1984; 97(748): 31-5.

23 Giles M, Asher I. Prevalence and natural history of otitis media with perforation in Maori school children. J. Laryngol. Otol. 1991; 105(4): 257-60.

24 Murphy S, Khaw KT, May H. Milk consumption and bone mineral density in middle aged and elderly women. $\mathrm{Br}$. Med. J. 1994; 308: 939-41.

25 CM Research. Consumer Monitor. Module One. Calcium/ Osteoporosis. Prepared for Dairy Advisory Bureau, New Zealand Dairy Board. Wellington: CM Research, 1998. 